\title{
BIBECHANA
}

A Multidisciplinary Journal of Science, Technology and Mathematics ISSN 2091-0762 (Print), 2382-5340 (Online)

Journal homepage: http://nepjol.info/index.php/BIBECHANA

Publisher: Research Council of Science and Technology, Biratnagar, Nepal

\section{Thermodynamic and structural investigations on mixing behavior of hetero-coordinated Al-based alloys in the fusion state}

\author{
I. Koirala ${ }^{1,2^{*}}$, B. P. Singh ${ }^{1}$, I. S. Jha ${ }^{3}$ \\ ${ }^{1}$ University Department of Physics, T.M. Bhagalpur University, India \\ ${ }^{2}$ Central department of physics, T.U. Kirtipur, Kathmandu, Nepal \\ ${ }^{3}$ M.M.A.M. Campus, Biratnagar, Tribhuvan University, Nepal \\ E-mail: ikphysicstu@gmail.com
}

Article history: Received 07 September 2015; Accepted 19 September, 2015

DOI: http://dx.doi.org/10.3126/bibechana.v13i0.13416

\section{Abstract}

We have used simple statistical model to report the hetero-coordination of two Al- based liquid alloys, i.e. $\mathrm{Al}-\mathrm{Ge}$ and $\mathrm{Al}-\mathrm{Fe}$ at temperatures $2000 \mathrm{~K}$ and $1873 \mathrm{~K}$ respectively. Through thermodynamic functions such as free energy of mixing and ratio of activity of the component atoms of the alloys, we have reported the information on the interaction, stability and bonding strength among the constituent atoms in the alloys. At the microscopic level, concentration fluctuation in the long wavelength limit and Warren-Cowely short range order parameter help to obtain the microscopic information on structure of molten alloys. Our theoretical analysis is based on interchange or ordering energy parameter which is found to be negative and temperature dependent. Negative deviation from Raoultian behaviour is observed in the computed thermodynamic and structural parameters of the alloys. The computed results are in good agreement with experimental data. The analysis concluded that both alloys are of weakly interacting and chemically ordered system.

ORCOST: All rights reserved.

Keywords: Simple statistical model; Negative deviation; Chemically ordered system; Activity ratio.

\section{Introduction}

Aluminium in pure state is ductile and relatively soft. To overcome this, the metal can be alloyed with other metals. Aluminium alloys with a wide range of properties are used in various engineering applications such as electrical conductors, transport, packaging, building, architecture etc. Selecting a right alloy for a given application entails considerations of strength, ductility, formability, weldability and corrosion resistance, to maintain a few. To obtain aluminium alloys which have the advantages of highly improved properties, the rapid solidification processing of aluminium alloys is being increasingly 
employed for their manufacture [1,2]. It is well known that during rapid solidification of alloys the arrangement or ordering alloys components in the liquid state have a considerable influence on the properties of the resulting solid. Al-Ge and Al-Fe are interesting aluminium based alloys. They exhibit phase diagram that show the system to behave as simple binary eutectic with mutual solubility [3, 4]. This suggests a tendency to regular alloys formation. Al-Ge alloys have been of interest in fundamental studies of nucleation in solid $[5,6]$ and in principle of precipitation reactions. The primary application of Al-Fe alloys is electrical distribution in the buildings with potential in automobiles, aerospace, telephone lines magnet winding [7-9]. Therefore theoretical investigation giving mixing properties of both alloys are highly desirable for the material preparation of the metal alloys. Several theoretical models [10-15] have long been proposed to understand mixing properties of binary liquid alloys. In present work, we study the concentration dependent mixing properties of liquid Al-Ge and Al-Fe at $2000 \mathrm{~K}$ and $1873 \mathrm{~K}$ respectively by the simple statistical model $[16,17]$.

The layout of this paper is arranged as follows: We present theoretical formalism in section 2, which is followed by results and discussions in section 3 and finally, we end the paper with a summary of concluding remarks in section 4.

\section{Theoretical formalism}

The excess free energy of mixing for binary alloys is obtained by solving the grand partition function in the framework of simple statistical model [16,17]. For regular solution which is given as

$$
\mathrm{G}_{\mathrm{M}}^{\mathrm{xS}}=\mathrm{RT} \int_{0}^{\mathrm{x}} \operatorname{In} \sigma^{\mathrm{z}} \mathrm{dx}=\mathrm{RT}\left\{\mathrm{xIn} \gamma_{\mathrm{A}}+(1-\mathrm{x}) \operatorname{In} \gamma_{\mathrm{B}}\right\}
$$

where $\sigma=(\beta+2 \mathrm{x}-1) \exp \left(-\omega / \mathrm{zk}_{\mathrm{B}} \mathrm{T}\right) / 2 \mathrm{x}$

$$
\begin{aligned}
& \gamma_{A}=[(\beta-1+2 x) / x(1+\beta)] z / 2 \\
& \gamma_{B}=[(\beta+1-2 x) /(1-x)(1+\beta)]^{z / 2} \\
& \beta=\left\{1+4 x(1-x)\left[\exp \left(2 \omega / z k_{B} T\right)-1\right]\right\}^{1 / 2}
\end{aligned}
$$

where $\mathrm{R}$ is universal molar constant; $\mathrm{T}$, absolute temperature; $\mathrm{x}$, concentration of the component; $\omega$, interchange energy; $\mathrm{z}$, coordination number and $\mathrm{k}_{\mathrm{B}}$, Boltzmann constant. For the ideal solution, the interaction between constituent atoms are identical $(\omega=0)$. Therefore the expression (1) becomes as

$$
\mathrm{G}_{\mathrm{M}}^{\mathrm{id}}=\mathrm{RT}\{\mathrm{x} \operatorname{Inx}+(1-\mathrm{x}) \operatorname{In}(1-\mathrm{x})\}
$$

Free energy of mixing is an important thermodynamic function which gives the knowledge about stability and interaction information of the constituent atoms in the alloys. Through standard thermodynamic relation as given below, we obtain the expression for free energy of mixing [17] as

$$
\mathrm{G}_{\mathrm{M}}=\mathrm{G}_{\mathrm{M}}^{\mathrm{id}}+\mathrm{G}_{\mathrm{M}}^{\mathrm{XS}}=\mathrm{RT}\{\mathrm{x} \ln \mathrm{x}+(1-\mathrm{x}) \ln (1-\mathrm{x})\}+\mathrm{RT}\left\{\mathrm{xIn} \gamma_{\mathrm{A}}+(1-\mathrm{x}) \operatorname{In} \gamma_{\mathrm{B}}\right\}
$$


For the equi-atomic composition $\left(\mathrm{x}=\frac{1}{2}\right)$, relation (1) reduces to

$$
\frac{\mathrm{G}_{\mathrm{M}}^{\mathrm{XS}}}{\mathrm{RT}}=\ln 2^{\mathrm{z} / 2}\left[1+\exp \left(-\omega / \mathrm{zk}_{\mathrm{B}} \mathrm{T}\right)\right]^{-\mathrm{z} / 2}
$$

The activity of binary liquid alloys is another fortune thermodynamic parameter which gives the nature and magnitude of interaction or bonding strength of the species of the alloys system. It can be evaluated from the free energy of mixing by the relation

$$
R T \ln \mathrm{a}_{\mathrm{i}}=\left(\frac{\partial \mathrm{G}_{\mathrm{M}}}{\partial \mathrm{N}_{\mathrm{i}}}\right)_{\mathrm{N}, \mathrm{P}, \mathrm{T}}=\mathrm{G}_{\mathrm{M}}+\left(1-\mathrm{x}_{\mathrm{i}}\right)\left(\frac{\partial \mathrm{G}_{\mathrm{M}}}{\partial \mathrm{x}_{\mathrm{i}}}\right)_{\mathrm{N}, \mathrm{P}, \mathrm{T}}
$$

Guggenheim zeroth approximation [18] yields the expression of activity of component atoms A and B from Eq.(3) and (5).Which are respectively,

$$
\begin{gathered}
a_{A}=x \exp \left\{\frac{\omega}{k_{B} T}(1-x)^{2}\right\} \\
a_{B}=(1-x) \exp \left\{\frac{\omega}{k_{B} T}(x)^{2}\right\}
\end{gathered}
$$

The ratio of activity of the component atoms (a) is given by

$$
\mathrm{a}=\frac{\mathrm{x}}{1-\mathrm{x}} \exp \left\{(1-2 \mathrm{x}) \frac{\omega}{\mathrm{k}_{\mathrm{B}} \mathrm{T}}\right\}
$$

Concentration fluctuations in the long-wavelength limit $\left(\mathrm{S}_{\mathrm{cc}}(0)\right)$ is an essential structural function which has been widely used to study the nature of atomic order in binary liquid alloys $[19,20] . S_{c c}(0)$ is thermodynamically related to free energy of mixing $\left(G_{M}\right)$ [19]. It is given as

$$
\mathrm{S}_{\mathrm{cc}}(0)=\mathrm{RT}\left(\frac{\partial^{2} \mathrm{G}_{\mathrm{M}}}{\partial \mathrm{x}^{2}}\right)_{\mathrm{T}, \mathrm{P}, \mathrm{N}}^{-1}
$$

Equations (3) and (9) gives the theoretical value of $\mathrm{S}_{\mathrm{cc}}(0)$ :

$$
\mathrm{S}_{\mathrm{cc}}(0)=\mathrm{x}(1-\mathrm{x})\left[1-\mathrm{x}(1-\mathrm{x}) 2 \omega / \mathrm{k}_{\mathrm{B}} \mathrm{T}\right]^{-1}
$$

The ideal value of concentration-concentration fluctuations, when the ordering energy is zero, is usually computed from:

$$
\mathrm{S}_{\mathrm{cc}}^{\mathrm{id}}(0)=\mathrm{x}(1-\mathrm{x})
$$

The Warren-Cowley [21, 22] short-range order parameter $\left(\alpha_{1}\right)$ is another useful structural parameter to quantify the degree of chemical order in the alloy melt. It provides insight into the local arrangement of the atoms in the molten alloys. Although it is difficult to obtain the experimental values of $\alpha_{1}$, theoretical values of this parameter are easily obtain via conditional probability [A/B] which defines the probability of finding an A-atom as a nearest neighbor of a given B-atom. It can be evaluated theoretically [21,22]: 


$$
\alpha_{1}=(\mathrm{S}-1) /\{\mathrm{S}(\mathrm{z}-1)+1\}, \quad \mathrm{S}=\mathrm{S}_{\mathrm{cc}}(0) / \mathrm{S}_{\mathrm{cc}}^{\mathrm{id}}(0)
$$

where $\mathrm{z}$ is the coordination number, which is taken as 10 for our purposes.

\section{Results and discussion}

For the computation of thermodynamic and structural functions of binary alloys, the basic input parameter is interchange energy $(\omega)$, which is concentration independent but dependent of temperature [23]. The interchange energy used for the calculation for Al-Ge and Al-Fe liquid alloys at respective temperature $1200 \mathrm{~K}$ and $1873 \mathrm{~K}$ has been determined from Eq. (3) or (4) by the method of successive approximation and comparing the results with the experimental value [24] of $G_{M}$ or $G_{M}^{X S}$ till the best fit value is obtained for the given alloys. The best fit values of the parameters for both alloys are given in table (1).

Table1: Basic parameter for the calculation.

\begin{tabular}{|l|c|c|c|}
\hline Alloys & $\mathrm{T}(\mathrm{K})$ & $\mathrm{z}$ & $\omega(\mathrm{ev})$ \\
\hline Al-Ge & $1200 \mathrm{~K}$ & 10 & -0.183 \\
$\mathrm{Al}-\mathrm{Fe}$ & $1873 \mathrm{~K}$ & 10 & -0.507 \\
\hline
\end{tabular}

The implications of $\omega$ in the table 1 being negative for both alloys considered for the study are chemically ordered. The value of inter change energy suggests that there is higher tendency for unlike atoms to pair in the alloys which implies that both are of hetero-coordination system. However, the tendency of pairing is weak since energy parameter is small.

The free energy of mixing for Al-Ge and Al-Fe liquid alloys have been computed from equation (3). The plot of $G_{M} / R T$ for both alloys with computed and experimental values against concentration of aluminium $\left(\mathrm{x}_{\mathrm{Al}}\right)$ are depicted in figure 1 . The computed values of $\mathrm{G}_{\mathrm{M}} / \mathrm{RT}$ for the both alloys systems, are in good agreement with the experimental data [24] in the whole range of concentration, $x_{\mathrm{Al}}=0.1$ to 0.9 . The minimum value of $\mathrm{G}_{\mathrm{M}} / \mathrm{RT}$ for Al-Ge is -1.1357 at $\mathrm{x}_{\mathrm{Al}}=0.5$ which almost matches with the experimental value at the same concentration. But for Al-Fe system at the same concentration $G_{M} / R T$ is found to minimum (-1.4782) which also matches with the observed data [24].From the analysis it is clear that both alloys systems are symmetric about equi-atomic composition. Further, the negative small values of free energy of mixing throughout the entire compositions indicate that the proposed alloys in molten state are weakly interacting system. 


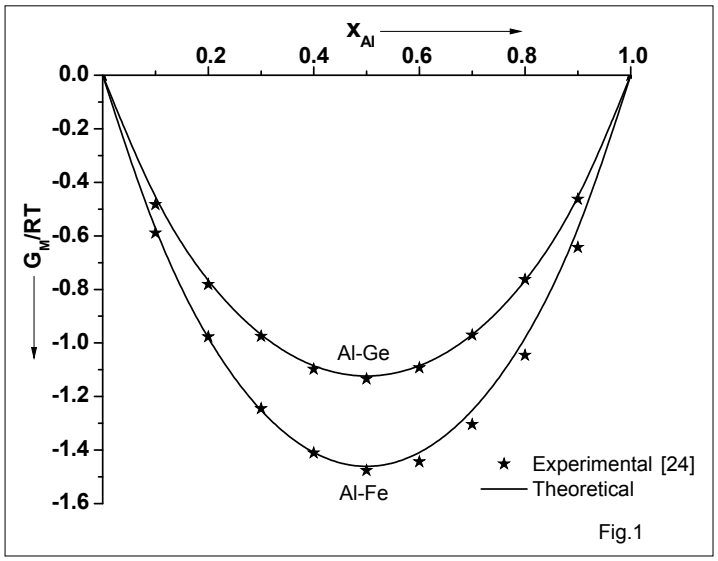

Fig.1: Free energy of mixing $\left(\mathrm{G}_{\mathrm{M}} / \mathrm{RT}\right)$ as a function of concentration $\left(\mathrm{x}_{\mathrm{Al}}\right)$ for $\mathrm{Al}-\mathrm{Ge}$ and $\mathrm{Al}-$ $\mathrm{Fe}$ liquid alloys at $2000 \mathrm{~K}$ and $1873 \mathrm{~K}$ respectively.

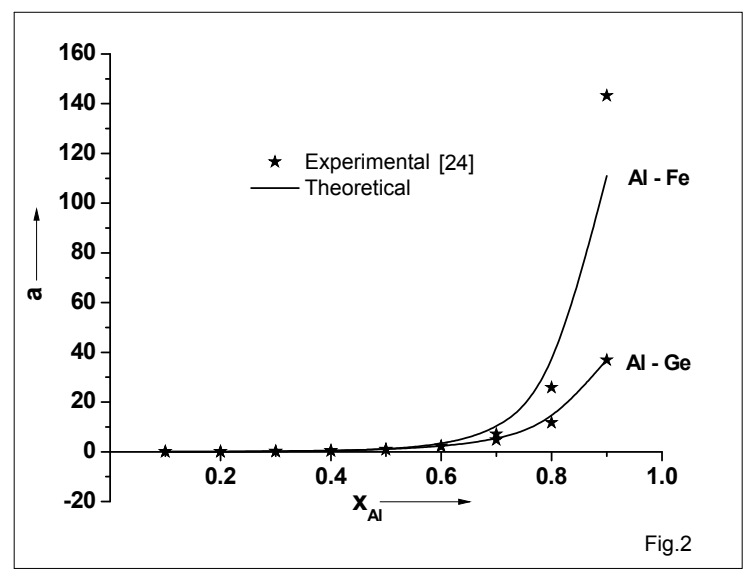

Fig.2: Activity ratio (a) as a function of concentration $\left(\mathrm{x}_{\mathrm{Al}}\right)$ for $\mathrm{Al}-\mathrm{Ge}$ and $\mathrm{Al}-\mathrm{Fe}$ liquid alloys at $2000 \mathrm{~K}$ and $1873 \mathrm{~K}$ respectively.

With respect to magnitude of $\mathrm{G}_{\mathrm{M}} / \mathrm{RT}$, we concluded that Al-Fe is more interacting system. The activity is one of the important thermodynamic functions which are obtained directly from experiment. The deviation from ideal behavior is incorporated into activity. Following the Eq.(8), we have computed the ratio of chemical activities of the components of the alloys by using the same value of the interchange energy which have been already used in free energy of mixing. The computed values of ratio of activities of the components of the alloys are plotted along with the experimental values against concentration is given in figure 2 . There is reasonable agreement between calculated and experimental values of ratio of activities of the components of the alloys. High activity ratio of Al-Fe suggests that ordering state of it is more as compared to Al-Ge system.

There are difficulties in diffraction experiment, therefore theoretical determination of $\operatorname{Scc}(0)$ is of great importance when nature of interactions in the melt has to be analyzed. The mixing behavior of liquid alloys can be deduced from the deviation of $\mathrm{S}_{\mathrm{cc}}(0)$ from $\mathrm{S}_{\mathrm{cc}}^{\mathrm{id}}(0)$. At a given composition if $\mathrm{S}_{\mathrm{cc}}(0)-\mathrm{S}_{\mathrm{cc}}^{\mathrm{id}}(0)=$ negative, ordering in liquid alloy is expected while $\mathrm{S}_{\mathrm{cc}}(0)-\mathrm{S}_{\mathrm{cc}}^{\mathrm{id}}(0)=$ positive; it gives the indication of tendency of segregation [19].

We have used Eq.(10) to compute the $S_{\mathrm{cc}}(0)$ for the alloys. It can also be obtained directly from the measured activity [24] data as

$$
S_{c c}=(1-x) a_{A}\left(\frac{\partial G_{M}}{\partial x}\right)^{-1}=x a_{B}\left(\frac{\partial G_{M}}{\partial(1-x)}\right)^{-1}
$$




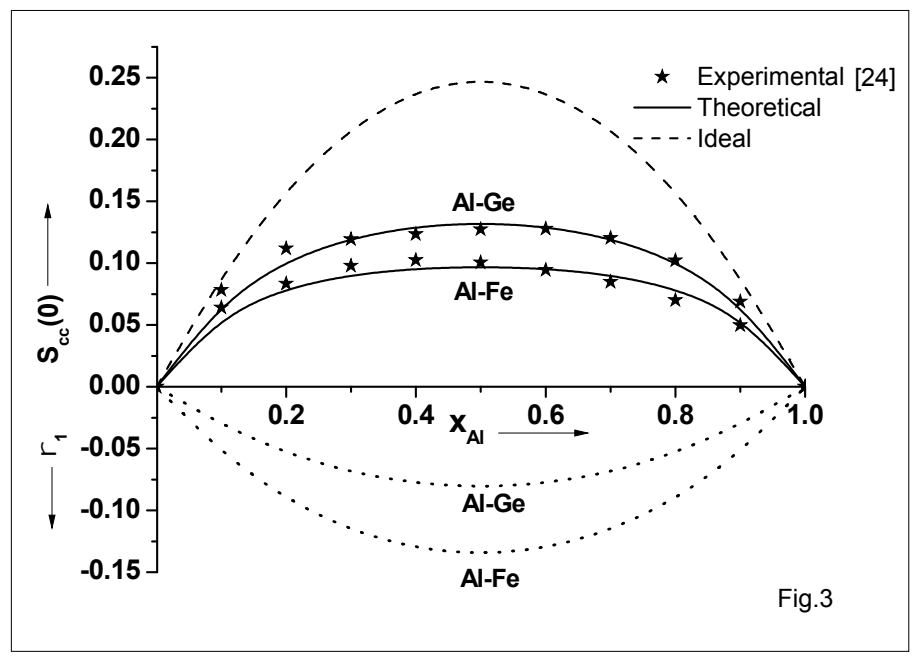

Fig.3: Concentration-concentration fluctuation in long wavelength limit $\left(\mathrm{S}_{\mathrm{cc}}(0)\right)$ and chemical short range order parameter $\left(\alpha_{1}\right)$ as a function of concentration $\left(\mathrm{x}_{\mathrm{Al}}\right)$ for Al-Ge and Al-Fe liquid alloys at $2000 \mathrm{~K}$ and $1873 \mathrm{~K}$ respectively.

where $\mathrm{a}_{\mathrm{A}}$ and $\mathrm{a}_{\mathrm{B}}$ are the observed chemical activities of $\mathrm{A}$ and $\mathrm{B}$ respectively of the alloys A-B. The $\mathrm{S}_{\mathrm{cc}}(0)$, obtained from Eq. (13) are taken as experimental values. Figure 3 shows a plot of the computed and experimental values of $\mathrm{S}_{\mathrm{cc}}(0)$ along with the ideal values as a function of concentration. The computed values of $S_{c c}(0)$ are in remarkable agreement with the experimental values of $S_{c c}(0)$ with little discrepancies. In the region $\mathrm{x}_{\mathrm{Al}} \quad 0.3$, discrepancy is observed between the computed and experimental values, which are due to size mismatch in the mixture. The result $S_{c c}(0)-S_{c c}^{i d}(0)=$ negative, clearly described both systems as compound forming. As $\mathrm{S}_{\mathrm{cc}}(0)$ for Al-Fe system is smaller than that of Al-Ge system, it confirms that Al-Ge is less ordered than Al-Fe system. The local ordering in the binary liquid alloys has been quantitatively described in terms of Warren-Cowley short range order parameter $\left(\alpha_{1}\right)$. For the equi-atomic composition, the chemical short range order parameter is found to be $-1 \leq \alpha_{1} \leq 1$. Negative values of $\alpha_{1}$ indicate ordering in the melt, which is complete if $\alpha_{1}=-1$. On the other hand, positive values of $\alpha_{1}$ indicate segregation, leading to complete only if $\alpha_{1}=1$. But $\alpha_{1}=0$, corresponds to random distribution of the atoms in the mixture. Figure 3 also shows the plots of $\alpha_{1}$ against chemical composition of aluminium, obtained from Eq. (12). It is observed that the plots are symmetrical about equi-atomic composition and negative throughout the whole concentration range of aluminium. The negative values of $\alpha_{1}$ (minimum at $\mathrm{x}_{\mathrm{Al}}=0.5$ ) throughout whole concentration range are the signatures of hetero-coordination system in the both alloys Al-Ge and Al-Fe. The magnitude of $\alpha_{1}$ (more negative) indicates that $\mathrm{Al}-\mathrm{Fe}$ system is more ordering than $\mathrm{Al}-\mathrm{Ge}$ alloys system.

\section{Conclusions}

Our theoretical analysis reveals that both alloys Al-Ge and Al-Fe systems respectively at $2000 \mathrm{~K}$ and $1873 \mathrm{~K}$ are chemically ordered. The free energy of mixing and concentration fluctuation in long 
wavelength limit deviates negatively from their ideality. In the overall calculation, interchange energy takes important role which is concentration independent but always dependent of temperature. From the nature and magnitude of free energy of mixing, concentration fluctuation in long wavelength limit, Warren-Cowley short range order parameter and activity ratio of the components of the respective alloys we concluded that both alloys are of weakly interacting system and comparatively liquid Al-Fe alloys is more chemically ordered than Al-Ge alloys.

\section{Acknowledgment}

One of the authors (I. Koirala) acknowledges Dr. Devendra Adhikari (Professor, M.M.A.M. Campus Biratnagar, Tribhuvan University, Nepal); and Dr. Lok Narayan Jha and Dr. Shekhar Gurung (Retired Professors, Tribhuvan University, Nepal) for fruitful suggestions and inspiring discussions.

\section{References}

[1] I. I. Tashlykova-Bushkevich, V. G. Shepelevich, J. Alloys Compd., 299(2009)205.

[2] E .J. Lavernia, J. D. Ayers, T. S. Srivaston, Int. Mater. Rev., 37(1992)1.

[3] W. G. Moffatt, The Handbook of Binary Phase Diagrams, General Electric Company, Schenectady, 1980.

[4] K. Fukutani, Y. Ishida, K. Tanji, T. Den, Thin solid films., 515(2007)4629.

[5] K. Kaneko, K. Inoke, K. Sato, K. Kitawaki, H. Higashida, I. Arslan, P. A. Midgley, Ultramicroscopy, 108 (2008)210.

[6] G. H. Deaf, Physica B, 348(2004)115.

[7] M. Schmucker, U .Koster, Mater. Sci .Eng.A, 133(1991)486.

[8] S. Hinderberger, S. Q. Xiao, K. H. Westmacott, U. Dahen, Z .Metallkd, 87(1996)161.

[9] B. C. Anusionwu, G. A. Adebayo, C. A. Madu, Applied Phys.A, 533(2009)97.

[10] L.C. Prasad, R.N. Singh, V.N. Singh, G.P. Singh, J. Phys. Chem. B, 921 (1998) 102.

[11] O. Akinlade, R. N. Singh, J. Alloys and Compounds, 333 (2002) 84.

[12] R. Novakovic, D. Giuranno, E. Ricci, A. Passerone, Surface Sci., 576 ( 2005) 175.

[13] D. Adhikari, I. S. Jha and B. P. Singh, Philosophical Mag-azine, 2687 (2010) 90.

[14] A .Kumar, I. S. Jha, B. P. Singh, Adv.Matt.Lett.,155 (2013),4.

[15] R. P. Koirala, I. S. Jha, B. P. Singh, D. Adhikari, J. .Mol. Liq., 179(2013)60.

[16] I. Koirala, B. P. Singh, I.S. Jha, J. Non-Cryst. Solids, 26 (2014) 398.

[17] R.N. Singh, I.K. Mishra, V.N. Singh, Phys. Condens. Matter, 8457 (1990) 2.

[18] E.A. Guggenheim, Mixtures, Oxford University Press, London, 1952.

[19] A. B. Bhatia, R.N. Singh, Phys. Chem. Liq., 343 (1982) 11.

[20] A. B. Bhatia, W.H. Hargoove, Phys. Rev. B, 3186 (1974) 10.

[21] B.E. Warren. X-ray Diffraction, Addison-Wesley, Reading MA, 1969.

[22] J. M. Cowley, Phys. Rev., 667 (1950) 77.

[23] I. Koirala, I. S. Jha, B. P. Singh, Bibechana, 70(2014)11.

[24] R. Hultgren, P.D. Desai, D.T. Hawkins, M. Gleiser, K.K. Kelley, Selected Values the of thermodynamic properties of binary alloys. ASM Metals Park, Ohio., 1973. 